NASA Contractor Report 156842

NASA-CR-156842

\title{
Lunar Tidal Acceleration Obtained From Satellite-Derived Ocean Tide Parameters
}

Clyde C. Goad

Bruce C. Douglas 


\section{Lunar Tidal Acceleration Obtained From Satellite-Derived Ocean Tide Parameters}

Clyde C. Goad and Bruce C. Douglas

National Oceanic and Atmospheric Administration

National Ocean Survey

Rockville, Maryland 20852

Prepared Under Purchase Order No. P62,871(G)

\section{N/SA}

National Aeronautics and Space Administration

Wallops Flight Center

Wallops Island, Virginia 23337

AC $804 \quad 824-3411$ 


$\begin{array}{lr}\text { INTRODUCTION } & 1 \\ \text { THE ORBIT OF GEOS-3 } & 3 \\ \text { COMPUTATION OF TIDAL PARAMETERS AND THE } & \\ \text { LUNAR TIDAL ACCELERATION } & 9 \\ \text { DISCUSSION } & 11 \\ \text { REFERENCES } & 14\end{array}$

\section{Preceding Page Blank}


Lambeck [1975] gives the ocean tide, $\xi$, as

$$
\begin{aligned}
& \xi_{\mu}=\sum_{s=0}^{\infty} \sum_{t=0}^{s} \sum_{i} P_{s t}(\sin \phi) . \\
& \left(C_{s t}^{ \pm}\right)_{\mu} \sin \left[\sigma(\tau) \pm t \lambda+\left(\varepsilon_{s t}^{ \pm}\right)_{\mu}\right]
\end{aligned}
$$

where the $\left(c_{s t}^{ \pm}\right)_{\mu}$ and $\left(\varepsilon_{s t}^{ \pm}\right)_{\mu}$ are functions of the spherical harmonic expansions of the $\mu$ tide component, and $\sigma(\tau)$ represents a linear combination of the solar and lunar angular quantities [Goad, 1977]. Lambeck [1975] also gives for the rate of change of the semi-major axis of the moon due to ocean tides

$$
\dot{a}=2 k_{\text {stuv }}^{\prime}(s-2 u+v)\left[\begin{array}{c}
\cos \\
\sin
\end{array}\right] \begin{gathered}
(s-t) \text { even } \\
\left(\varepsilon_{s t}^{+} t^{\prime}{ }^{\prime},\right.
\end{gathered},
$$

where $k_{\text {stuv }}^{\prime}$ is a function of the orbital semi-major axis, inclination, eccentricity, Earth and lunar masses, mean density of the Earth and oceans, the load deformation coefficient, and particularly the coefficient $\mathrm{C}_{s t}^{+}$as a linear factor. From elementary celestial mechanics, the secular change in the mean motion, $n$, of the moon is given by,

$$
\dot{n}=-\frac{3}{2} \quad \frac{n}{a} \quad \dot{a} \text {. }
$$

The critical factor in computing the tidal acceleration $\dot{n}$ of the moon is shown to be the quantity

$$
\mathrm{C}_{22}^{+} \cos \varepsilon_{22}^{+}
$$

and Lambeck [1975] notes that for three different global $M_{2}$ ocean tide models this quantity varies by only $10 \%$ from the mean of the three. Taking this mean value for the dominant $M_{2}$ tide effect, the results by Dietrich for the $0_{1}$ tide, and estimating the $\mathrm{N}_{2}$ tide as proportional to the corresponding tide raising $M_{2}$ and $N_{2}$ potentials, Lambeck [1975] obtains the estimate

$$
\dot{\mathrm{n}}=-35 \pm 4 \mathrm{arc}-\mathrm{sec} /(100 \mathrm{yr})^{2}
$$


for the lunar tidal acceleration if it is assumed that there is no contribution from a solid tide phase lag. He further notes that astronomically obtained values at the time of his publication ranged from -37 to -52 arc$\mathrm{sec} /(100 \mathrm{yr})^{2}$. Subsequently, the values estimated from astronomical data $\dot{n}_{t}=-27.2 \pm 1.7$ and $\dot{n}_{t}=-26 \pm 2$ have been obtained by Muller [1976] and Morrison and Ward [1976], respectively.

Artificial satellites can help resolve this problem because results obtained from them are independent of lunar or planetary data and do not require knowledge of any tidal mechanisms. However, until very recently there were no reliable estimates of $M_{2}$ ocean tide parameters from satellite orbit perturbations.

Previously, we published a constraint equation on the $M_{2}$ ocean tide coefficients that was in reasonable agreement with numerical ocean tide models. [Goad and Douglas, 1977]. In the present paper we obtain additional equations from an analysis of the evolution of the orbit of GEOS- 3 that enable an explicity solution for $\mathrm{C}_{22}^{+} \cos \varepsilon_{22}^{+}$for the $M_{2}$ tide and hence an estimate for the tidal acceleration of the moon. Our value of $(-27.6$ arc$\left.\mathrm{sec} /(100 \mathrm{yr})^{2}\right)$ is in agreement with the recent solution of Muller [1976] and Morrison and Ward [1975]. 
Table 1 gives the orbital specifications of GEOS-3. 0sculating orbit elements for 100 successive two-day arcs were obtained from the Doppler. tracking done in support of the GEOS-3 program by the Naval Surface Weapons Center (NSWC), Dahigren, Virginia. The mean elements corresponding to the osculating elements are given in Table 2. All long periodic and secular perturbations are present in these elements. We have analyzed extensively only the mean inclination and node. The precision of the mean inclination is about 0:"02. The mean node is less accurate (about 0."04) primarily due to the uneertainty of the prediction of UTI time used in the data reductions.

Table 3 gives the perturbation on the inclination and node of GEOS-3 computed from our solution for the $(2,2)^{+}$and $(4,2)^{+}$coefficients. A detailed discussion of the tidal perturbations on satellite orbits is given by Lambeck et al., [1974]. We have used the results of that work for our own computations with the exception of eq. 6, p. 424 for the perturbation of the node. We are unable to verify this equation. Our application of the differential equation for the time rate of change of the node to the tidal potential developed by Lambeck et al. [1974] is

$$
\begin{aligned}
& \Delta \Omega_{n \ell m p q}^{ \pm}=\frac{4 \pi\left(1+k_{\ell}^{\prime}\right)}{2 \ell \ell+1} G a\left(\frac{a}{a}\right)^{\ell+1} \frac{\rho_{w}}{N a^{2}\left(1-e^{2}\right)^{\frac{1}{2}} \sin i} c_{n \ell m}^{ \pm} G_{\ell p q}(e) \\
& \frac{1}{\dot{\gamma}^{ \pm}}\left\{\frac{\partial F_{\ell m p}(i)}{\partial i}-\frac{3}{2} N\left(\frac{a e}{a}\right)^{2} \frac{c_{20} \sin i}{\left(1-e^{2}\right)^{2}} F_{\ell m p}(i) \frac{[(\ell-2 p) \cos i-m]}{\dot{\gamma}^{ \pm}}\right\} \\
& {\left[\begin{array}{c}
\mp \\
\mp \\
\mp \sin
\end{array}\right]_{\ell-m \text { odd }}^{r_{n \ell m p q}^{ \pm}}}
\end{aligned}
$$




\section{Table 1. GEOS-3 Orbital Characteristics}

Epoch MJO 42525.0

a $7219 \mathrm{~km}$

$\overline{\mathrm{e}} \quad .0005$

$\bar{i} \quad 114: 99$

Perigee Altitude

$\mathrm{M}_{2}$ Tidal Period
April 23, 19750 hrs.

$837 \mathrm{~km}$

$17^{d} .2$ 
Table 2. Mean Keplerian Elements (GEOS-3)

\begin{tabular}{|c|c|c|c|c|c|c|}
\hline & (MET́ERS) & E & $\begin{array}{c}\prime \\
\text { (OEGREES) }\end{array}$ & $\begin{array}{c}\text { MODE } \\
\text { (OEGREES) }\end{array}$ & $\begin{array}{l}\text { PERIGEE } \\
\text { (DEGREES) }\end{array}$ & (DEGREES) \\
\hline 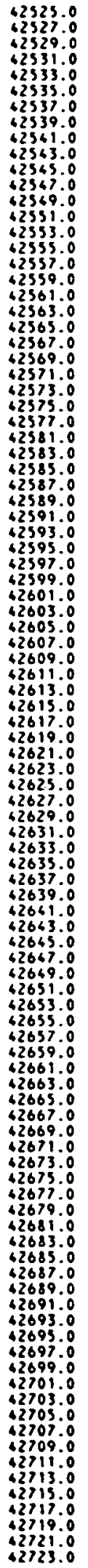 & 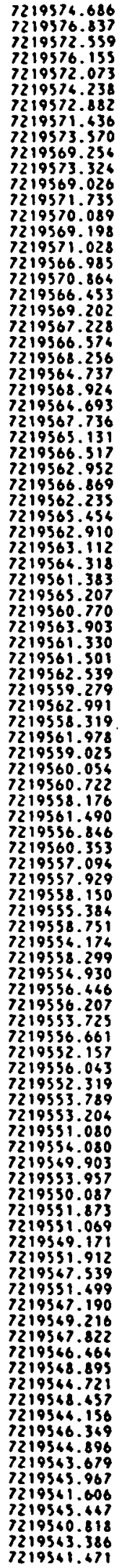 & 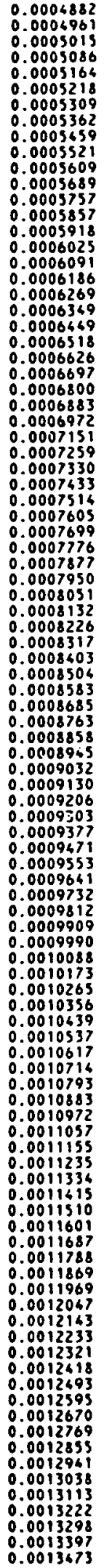 & 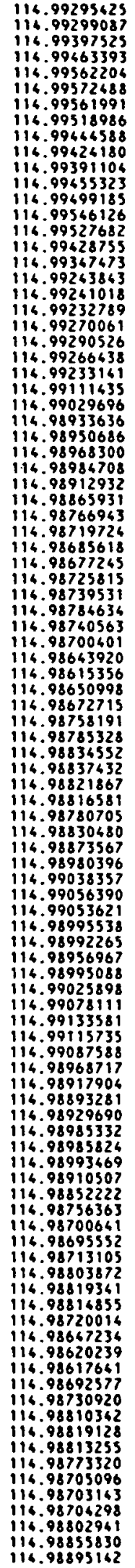 & 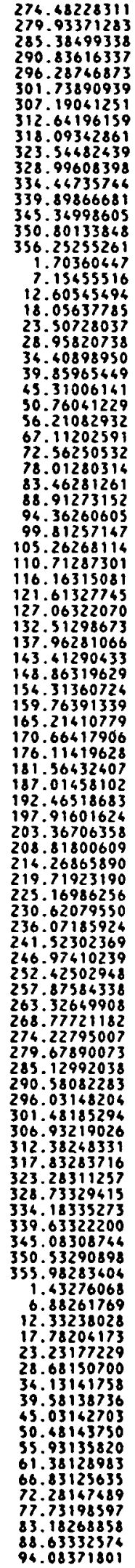 & 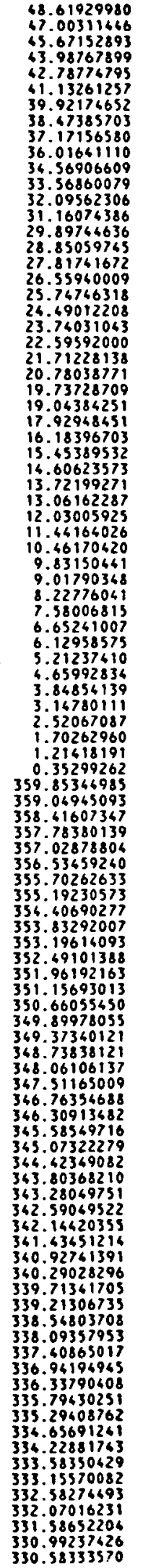 & 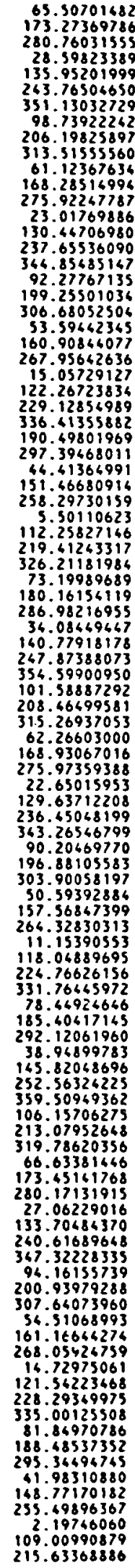 \\
\hline
\end{tabular}


Table 3. Amplitude and phase of inclination and node perturbations due to the $M_{2}$ ocean tide on GEOS-3 satellite.

\begin{tabular}{|c|c|c|c|c|}
\hline \multirow{2}{*}{$\frac{\text { Source }}{\text { Observed }}$} & \multicolumn{2}{|c|}{$\begin{array}{c}\text { Inclination } \\
\text { Amplitude Phase }\end{array}$} & \multicolumn{2}{|c|}{$\begin{array}{c}\text { Node } \\
\text { Amplitude Phase }\end{array}$} \\
\hline & $0: 040$ & $327^{\circ}$ & 0.027 & $291^{\circ}$ \\
\hline Pekeris and Accad* & $0 " .051$ & $339^{\circ}$ & 0.030 & $352^{\circ}$ \\
\hline Hendershott (Mode1 1)* & 0.061 & $317^{\circ}$ & $0: 030$ & $286^{\circ}$ \\
\hline Hendershott (Mode1 2)* & $0: 065$ & $276^{\circ}$ & 0.025 & $244^{\circ}$ \\
\hline Bogdanov and Magarik* & $0: 050$ & $328^{\circ}$ & 0.049 & $290^{\circ}$ \\
\hline
\end{tabular}

* As reported by Lambeck et al. [1974]. 
The difference appears in the indirect term arising from the interaction with the Earth's oblateness [Kaula, 1966, p. 49].

Note in Table 3 that the ocean tide effects on GEOS-3 are rather different on the inclination and node. The perturbation on the inclination comes almost entirely from the $(2,2)$ term and that of the node from the $(4,2)$ term. Using the methods employed in our previous paper [Goad and Douglas, 1977] to remove known perturbations, we obtain the observation equations for the $M_{2}$ ocean tides:

Inclination:

$$
\begin{aligned}
& (3 ! 99 \pm 0.4) \times 10^{-2} \sin \left[\sigma(\tau)+327^{\circ} \pm 4^{\circ}\right] \\
= & \frac{1 ! 26}{\mathrm{~cm}} \times 10^{-2} \mathrm{C}_{22}^{+} \sin \left[\sigma(\tau)+\varepsilon_{22}^{+}\right]-\frac{0 ! 32}{\mathrm{~cm}} \times 10^{-2} \mathrm{C}_{42}^{+} \sin \left[\sigma(\tau)+\varepsilon_{42}^{+}\right]+\ldots
\end{aligned}
$$

Node:

$$
\begin{aligned}
& (2.73 \pm 0.7) \times 10^{-2} \cos \left[\sigma(\tau)+291^{\circ} \pm 13^{\circ}\right] \\
= & -\frac{0.24}{\mathrm{~cm}} \times 10^{-2} c_{22}^{+} \cos \left[\sigma(\tau)+\varepsilon_{22}^{+}\right]-\frac{3.38}{\mathrm{~cm}} \times 10^{-2} c_{42}^{+} \cos \left[\sigma(\tau)+\varepsilon_{42}^{+}\right]+\ldots
\end{aligned}
$$

These equations can be used for a GEOS-3 solution alone for $(2,2)^{+}$and $(4,2)^{+}$ quantities because the node and inclination on GEOS-3 have negligible correlation [Anderle, 1977, private communication]. However, a combined solution with 1967-92A yields more precise results. To demonstrate the precision of the GEOS-3 inclination data, we have prepared Figure 1 to show the observed and calculated values of the $M_{2}$ ocean tide perturbation of the inclination of GEOS-3. 


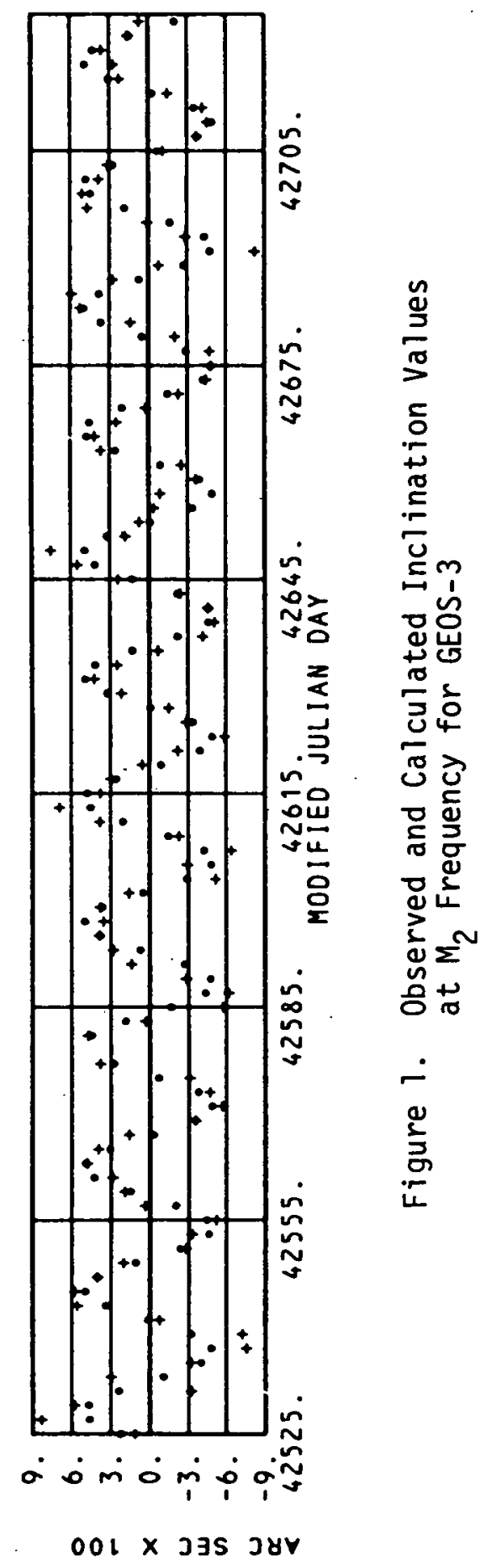

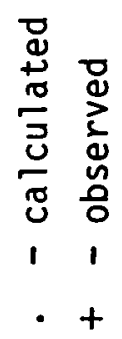




\section{COMPUTATION OF TIDAL PARAMETERS AND THE LUNAR TIDAL ACCELERATION}

As shown by Lambeck et al. [1974], computation of ocean tide parameters from satellite orbit perturbations requires assumption of values for the solid tide Love number $k_{2}$ and the lag angle. Table 4 gives the results for ocean tidal parameters for various values of the solid tide phase lag with $k_{2}$ assumed to be 0.30 , a value often quoted from seismic measurements.

Note in Table 4 that increasing the solid phase lag results in a large reduction in the value of $\mathrm{C}_{22}^{+}$, until at $1^{\circ}$ the value of either the GEOS-3 or the combined GEOS-3/1967-92A solution falls to less than $1 / 2$ of the value obtained by Hendershott (quoted in Lambeck et a].[1974]). Thus, although solid and ocean tide effects on satellite orbits cannot be separated, assumption of a solid tide phase lag as large as $1^{\circ}$ leads to unacceptable values for the ocean tide coefficients with $k_{2}=0.30$.

Using the combined GEOS-3/1967-92A results for the $M_{2}$ tide coefficients in the equations for $\dot{a}, \dot{n}$ and using the values given by Lambeck [1975] for the $0_{1}$ and $N_{2}$ values, we obtain the value $\dot{n}=-27.6 \pm 3$ arc sec/ $(100 \mathrm{yr})^{2}$. Muller [1976] obtained $-27.2 \pm 1.7$; and Morrison and Ward [1976] obtained $-26 \pm 2$. All of these values are outside the range of -35 to $-52 \mathrm{arc} \mathrm{sec} /$ $(100 \mathrm{yr})^{2}$ reported in Lambeck [1975]. 


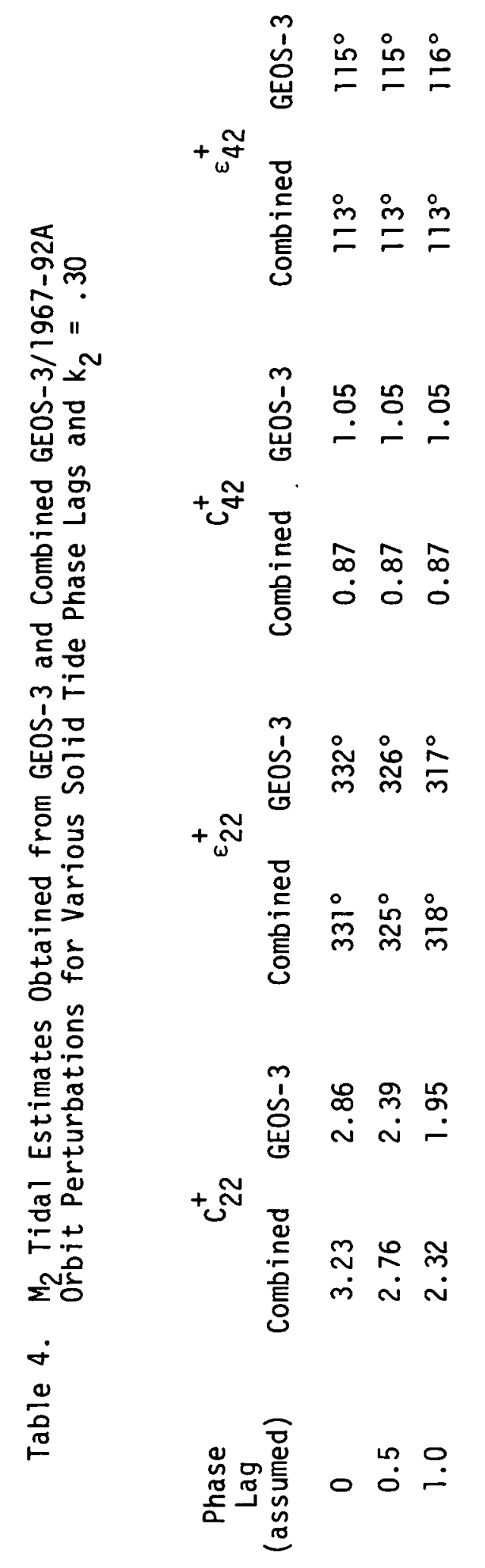




\section{DISCUSSION}

The formal uncertainty of our solution for the $M_{2}$ tide parameters corresponds to $\pm 1.8 \mathrm{arc} \mathrm{sec} /(100 \mathrm{yr})^{2}$ in $\dot{\mathrm{n}}_{\mathrm{t}}$. However, the $0_{1}$ and $\mathrm{N}_{2}$ tides also contribute about $-4.4 \mathrm{arc} \mathrm{sec} /(100 \mathrm{yr})^{2}$ total lunar tidal acceleration. Because of the very approximate way in which parameters for these latter tidal components were estimated by Lambeck [1975], an uncertainty of perhaps $25 \%$ in the $O_{1}$ and $\mathrm{N}_{2}$ contributions is conceivable, leading to an additional source of uncertainty of at least one $\operatorname{arcsec} /(100 \mathrm{yr})^{2}$. Therefore, we estimate the total uncertainty of our value of the tidal $\dot{n}$ for the moon to be $\pm 3 \operatorname{arc~sec} /(100 \mathrm{yr})^{2}$.

Another significant matter is concerned with the effect of a non-zero but small solid tide phase lag $\delta_{2}$. Again assuming that the Love number $k_{2}$ has the value of 0.30 , the total solid and fluid lunar tidal acceleration is given by

$$
\begin{aligned}
\dot{n}_{\text {total }}= & -1040 k_{2} \sin \left(2 \delta_{2}\right)-8.32 C_{22}^{+} \cos \varepsilon_{22}^{+} \\
& -4.4\left(N_{1}+O_{2}\right)
\end{aligned}
$$

arc sec/(1-0 yr $)^{2}$ where the last term is that given by Lambeck [1975]. However, the affect of a non-zero value of $\delta_{2}$ in a satellite solution for ocean tide parameters results in a compensating change in $\mathrm{C}_{22}^{+} \cos \varepsilon_{22}^{+}$that maintains a nearly constant value for the total $\dot{n}$. For example, assumption of $\delta_{2}=0.5^{\circ}$ changes the value of the total solid/fluid $\dot{n}$ by only 1 arc sec/(100 $\left.\mathrm{yr}\right)^{2}$. Thus our value for the lunar tidal acceleration is insensitive to any small future adjustments of the value of $\delta_{2}$.

Finally, some consideration is required of the method used by Lambeck to obtain the 2nd degree spherical harmonic coefficients from numerical ocean tide models. Lambeck [1975] notes that the three $M_{2}$ tide models he used to estimate the lunar $\dot{n}$ vary by $10 \%$ about their mean value for $C_{22}^{+} \cos \varepsilon_{22}^{+}$. However, his procedure for obtaining the coefficients can introduce considerable uncertainty into the process. For two of the models he obtained values of 
the tidal amplitude and phase at a $10^{\circ}$ grid interval and then expanded the values in a series of harmonics. We decided to test the effect of grid-size on the coefficient estimates. E. Schwiderski (NSWC), provided us with the $M_{2}$ tidal phase and amplitude at each $1^{\circ}$ of latitude and longitude based upon his latest numerical solution of the Laplace tidal equations. This model is being used in the analysis of satellite altimeter data at the NSWC (Schwiderski, 1977). Table 5 shows that the value of the critical $c_{22}^{+} \cos _{22}^{+}$term does depend on the grid interval by (in this case) an amount corresponding to as much as 5.4 arc sec/ $(100 \mathrm{yr})^{2}$. Thus it is critical in future analyses of numerical ocean tide models to compute spherical harmonic coefficients from data gridded at much finer than $10^{\circ}$ intervals. It is also worth noting that the $\dot{n}_{t}$ obtained with zero solid phase lag and the Schwiderski ocean tide parameters is -28.9 arc sec/ $(100 \mathrm{yr})^{2}$. No information is available to estimate the uncertainty of this result.

In spite of new results for the lunar tidal accelerations smaller in absolute value than $\dot{n}_{t}=-30 \mathrm{arc} \mathrm{sec} /(100 \mathrm{yr})^{2}$, the source of this acceleration can be accounted for by the ocean tides alone. The $(2,2)^{+}$term in the expansion of the ocean tides is equivalent to an equatorial bulge that leads the moon by $55^{\circ}$ so that even though the amplitude is small compared to solid tide, the torque produced is large.

The results from perturbations of artificial satellites are especially satisfying because no knowledge of tidal mechanisms is required to obtain the principal component of the expansion of the ocean tides in spherical harmonics that is responsible for the lunar tidal acceleration. New, accurate numerical tide models for the $0_{1}$ and $N_{2}$ tides would be useful in further refining the results presented here. 
Table 5. Effect of Grid Size on Estimates of Tidal Parameters

$\begin{array}{cccc}\text { Grid Interva1, deg. } & c_{22}^{+} & \varepsilon_{22}^{+} & c_{22}^{+} \cos \varepsilon_{22}^{+} \\ 10 \times 10 & 3.26 & 325 & 2.67 \\ 8 \times 8 & 3.81 & 331 & 3.33 \\ 5 \times 5 & 3.38 & 325 & 2.76 \\ 3 \times 3 & 3.65 & 325 & 2.99 \\ 1 \times 1 & 3.59 & 326 & 2.98\end{array}$




\section{REFERENCES}

Goad, C. C., Application of digital filtering to satellite geodesy, NOAA Technical Report NOS71 NGS6, U. S. Dept. of Commerce, National Oceanic and Atmospheric Administration, National Ocean Survey, Rockville, MD, 1977.

Goad, C. C. and B. C. Douglas, Determination of $M_{2}$ ocean tide parameters from satellite orbit perturbations, J. of Geophys. Res., 82, 898-900, 1977.

Kaula, W. M., Introduction to Satellite Geodesy, Blaisdell, Waltham, Mass., 124 pp., 1966.

Lambeck, K., Effects of tidal dissipation in the oceans on the moon's orbit and the earth's rotation, J. Geophys. Res., 80, 2917-2925, 1975.

Lambeck, K., A. Cazenaye, and G. Balmino, Solid earth and ocean tides estimated from satellite orbit analyses, Reviews of Geophysics and Space Physics, 12, 421-434, 1974.

Morrison, L. V. and C. G. Ward, An analysis of the transits of Mercury 1677-1973, Monthly Notices of Royal Astronomical Society, 173, London, 183-206, 1975.

Muller, P. M., Determination of the cosmological rate of change of $G$ and the tidal accelerations of earth and moon from ancient and modern astronomical data, JPL Special Publication 43-36, Jet Propulsion Laboratory, Pasadena, CA, 1976.

Schwiderski, E. W., Ocean tides and GEOS-3. Presented at the AGU Annual Spring Meeting, Washington, D.C., May 30-June 3, 1977. 


\begin{tabular}{|c|c|c|c|}
\hline $\begin{array}{l}\text { 1. Report No. } \\
\text { NASA CR-156842 }\end{array}$ & 2. Government Accession No. & \multicolumn{2}{|c|}{ 3. Recipient's Catalog No. } \\
\hline \multicolumn{2}{|l|}{ 4. Title and Subtitle } & \multicolumn{2}{|c|}{$\begin{array}{l}\text { 5. Report Date } \\
\text { October } 1978\end{array}$} \\
\hline \multicolumn{2}{|c|}{$\begin{array}{l}\text { Lunar Tidal Acceleration Obtained from Satellite-Derived } \\
\text { Ocean Tide Parameters }\end{array}$} & \multicolumn{2}{|c|}{ 6. Performing Organization Code } \\
\hline \multirow{2}{*}{\multicolumn{2}{|c|}{$\begin{array}{l}\text { 7. Author(s) } \\
\text { Clyde C. Goad and Bruce C. Douglas }\end{array}$}} & \multirow{2}{*}{\multicolumn{2}{|c|}{ 8. Performing Organization Report No. }} \\
\hline & & & \\
\hline \multirow{3}{*}{\multicolumn{2}{|c|}{$\begin{array}{l}\text { 9. Performing Organization Name and Address } \\
\text { National Oceanic and Atmospheric Administration } \\
\text { National Ocean Survey } \\
\text { Rockville, Maryland } 20852\end{array}$}} & \multicolumn{2}{|l|}{ 10. Work Unit No. } \\
\hline & & \multicolumn{2}{|c|}{$\begin{array}{l}\text { 11. Contract or Grant No. } \\
P 62,871(G)\end{array}$} \\
\hline & & \multicolumn{2}{|c|}{$\begin{array}{l}\text { 13. Type of Report and Period Covered } \\
\text { Final Report }\end{array}$} \\
\hline \multicolumn{2}{|c|}{$\begin{array}{l}\text { 12. Sponsoring Agency Name and Address } \\
\text { National Aeronautics and Space Administration } \\
\text { Wallops Flight Center } \\
\text { Wallops Island, Virginia } 23337\end{array}$} & \multicolumn{2}{|c|}{ 14. Sponsoring Agency Code } \\
\hline \multicolumn{4}{|l|}{ 15. Supplementary Notes } \\
\hline \multicolumn{4}{|c|}{ 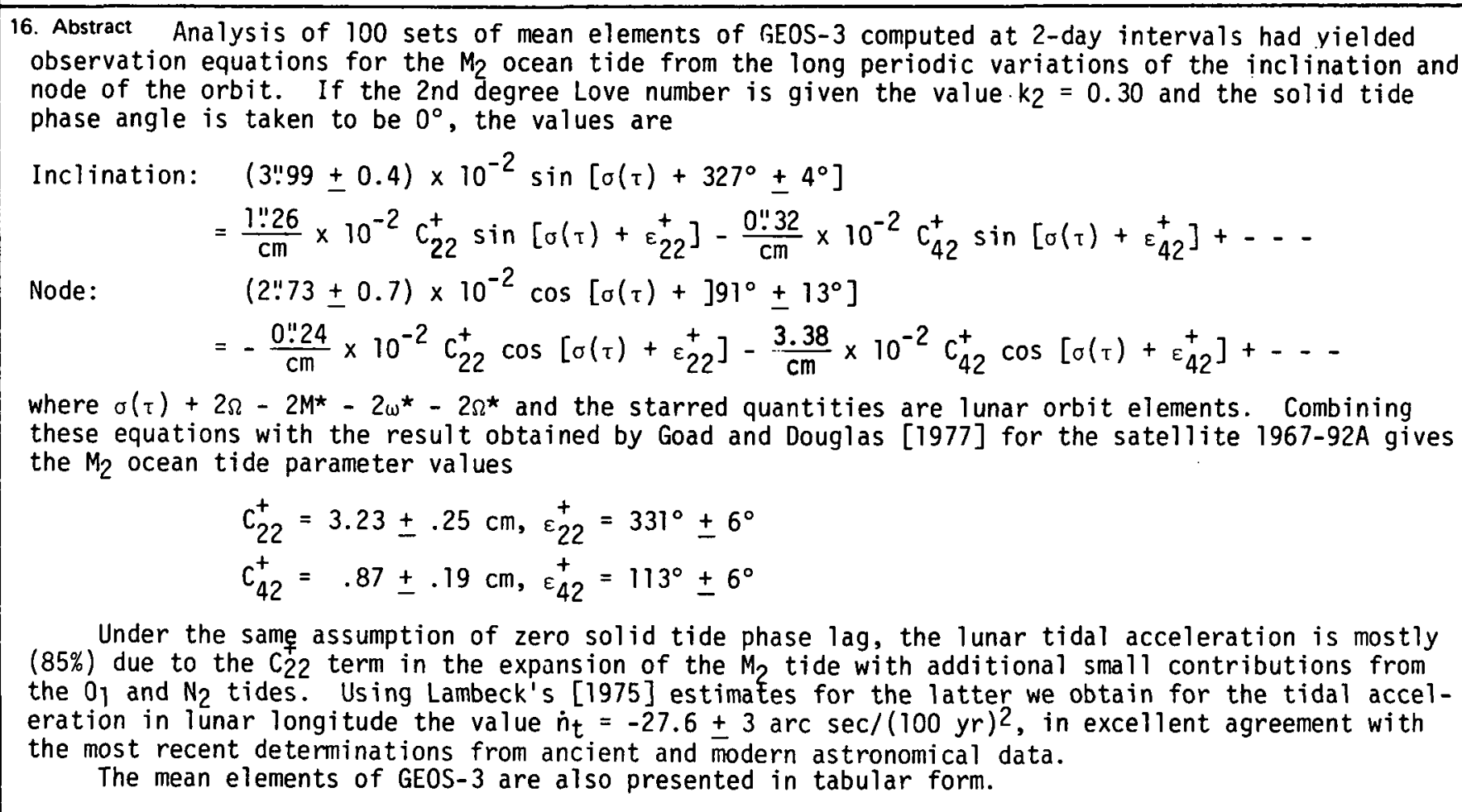 } \\
\hline \multicolumn{2}{|c|}{$\begin{array}{l}\text { 17. Key Words (Suggested by Author(s)) } \\
\text { GEOS- } 3 \\
\text { tides } \\
\text { Love numbers }\end{array}$} & \multicolumn{2}{|c|}{$\begin{array}{l}\text { 18. Distribution Statement } \\
\text { Unclassified - unl imited } \\
\text { STAR category - } 13,42,46,48\end{array}$} \\
\hline $\begin{array}{l}\text { 19. Security Classif. (of this report) } \\
\text { Unclassified }\end{array}$ & $\begin{array}{l}\text { 20. Security Classif. (of this page) } \\
\text { Unclass ified }\end{array}$ & $\begin{array}{l}\text { 21. No. of Pages } \\
14\end{array}$ & 22. Price* \\
\hline
\end{tabular}

"For sale by the National Technical Information Service, Springfield, Virginia 22151 